\title{
LAs Cortes Supremas COMO MECANISMO DE DISTRIBUCIÓN DE PODER: EL CASO DE LA REELECCIÓN PRESIDENCIAL EN COSTA RicA Y NiCARAGUA
}

\author{
Supreme Courts as a Mechanism of 'Allocation of Power': \\ The Case of Presidential Reelection in Costa Rica and Nicaragua
}

\section{ELENA MARTÍNEZ-BARAHONA*}

Universidad de Salamanca

\begin{abstract}
RESUMEN
Recientemente dos países de la región centroamericana han aprobado la reelección presidencial gracias a sendas decisiones de sus Cortes Supremas. El objetivo de este artículo es examinar por qué se ha transferido la decisión sobre este tema al foro judicial en lugar de seguir la correcta vía legislativa. Para explicar esta situación se propone un modelo que muestra que la cuestión de la reelección se trasladará a los foros judiciales cuando exista una fuerte división o fragmentación en la Asamblea, el candidato pertenezca a una coalición ascendente y existan Cortes proactivas y orientadas políticamente. El análisis empírico que respalda el modelo considera las dos decisiones de la Corte Supremas de Costa Rica y Nicaragua que han permitido la reelección presidencial en dichos países.
\end{abstract}

Palabras clave: Cortes Supremas, reelección presidencial, políticas judiciales, Costa Rica, Nicaragua.

\begin{abstract}
Two Central American countries have recently approved the presidential reelection by a Supreme Court decision. This article propose a model to explain why this decision has been taken in a judicial institution instead of the correct legislative arena. The model shows that the decision about this question will be trasferred to the judicial forum when the National Assembly is fragmented, the promoter is a "growing coalition" and the Supreme Court is "goal-oriented" This model is supported by an empirical analysis of the Supreme Court decision affecting presidential electoral rules that took place in Costa Rica and Nicaragua.
\end{abstract}

Key words: Supreme Courts, presidential reelection, judicial politics, Costa Rica, Nicaragua.

* Quiero agradecer los comentarios y sugerencias realizados por los evaluadores anónimos de RCP que me han permitido mejorar la versión previa del artículo. Del mismo modo agradezco también y especialmente las críticas de Sebastián Linares y las orientaciones de Diego Brenes y Amelia Brenes respecto al caso costarricense. 


\title{
1. LAS CORTES SUPREMAS Y SU FUNCIÓN DE “ALLOCATION OF POWER"
}

\begin{abstract}
"In democratic states, most government officials achieve legitimacy by acknowledging their political role and claiming subordination to the people through elections or responsibility to those elected. Judges, however, claim legitimacy by asserting that they are non-political, independent, neutral servants of 'the law'. Alone among democratic organs of government, Courts achieve legitimacy by claiming they are something they are not"
\end{abstract}

(Shapiro y Stone Sweet, 2002: 3).

Que las Cortes son actores políticos ya es indudable. Numerosos estudios se han escrito al respecto tanto a nivel mundial como a nivel regional. ${ }^{1}$ Sin embargo, aunque no son muchos los trabajos que se han dedicado a conceptualizar de un modo sistemático el papel que desarrollan las Cortes Supremas, sigue siendo fundamental profundizar en los diferentes roles que desempeñan para poder así entender su nueva posición dentro de los sistemas políticos contemporáneos.

En este sentido, podríamos clasificar en cuatro categorías las funciones políticamente relevantes de las Cortes Supremas y que se desprenden de su función de revisión judicial: ${ }^{2}$

(a) La función de revisión de políticas públicas. Las Cortes Supremas pueden redefinir políticas que han sido ya decididas previamente por agentes políticos (Legislativo o Ejecutivo), influyendo así en el proceso de deliberación pública. En este sentido Volcansek (2001: 367) indica que "although courts cannot directly initiate nor enforce policies, they can, nonetheless, influence policy change in several ways" Así el poder de declarar actos del Ejecutivo o del Legislativo inconstitucionales no sólo funciona como control, sino también como una decisión política que transforma a las Cortes en relevantes actores del sistema.

(b) La función de rendición de cuentas o función de accountability que recoge la capacidad de controlar los abusos en el ejercicio del poder por otros órganos políticos. Esta función se refiere al poder de las Cortes para actuar como órganos de control de los excesos del Ejecutivo o del Legislativo en los casos de corrupción y para ofrecer protección legal de los abusos arbitrarios contra los derechos humanos. La intervención en delitos políticos o la alta visibilidad y crecimiento de la justicia penal en los procesos políticos ha sido llamada "criminalización de la responsabilidad política" (Sousa Santos, 1996). En América Latina esta función judicial es una de las más relevantes dado que las cuestiones de corrupción e impunidad representan uno de los mayores obstáculos para la consolidación democrática.

1 Aunque es imposible hacer aquí una referencia exhaustiva a toda la literatura académica sobre "judicial politics" en la región latinoamericana, se podrían señalar como importantes los trabajos recopilatorios llevados a cabo por Kapizeswki y Taylor (2008), Tate (2007) o Ansolabehere y Martínez-Barahona (2009).

2 Esta clasificación se corresponde con una tipología revisada de un trabajo anterior (Martínez-Barahona, 2009). 
(c) La función de la revision constitucional haría referencia al papel decisivo que tienen las Cortes Supremas cuando realizan interpretaciones constitucionales. Sin embargo, Tsebelis (2002: 228) indica que la importancia política que tienen las Cortes cuando llevan a cabo una interpretación constitucional reside en que funcionan como agenda-setter poniendo en la agenda pública nuevos temas antes no considerados o considerados de un modo diferente. ${ }^{3}$

(d) La función de distribución de poder hace referencia a la capacidad de las Cortes Supremas de influir a través de sus casos en la reasignación de poder en el sistema político de un determinado país.

Este artículo se centrará en estas dos últimas funciones mediante el estudio de una de las cuestiones políticas más relevantes, polémicas y actuales que se están decidiendo en la región latinoamericana y que tiene relación directa con la esfera jurisdiccional: la reelección presidencial y por qué la decisión sobre la misma en algunos países se está trasladando a las altas instancias judiciales. Costa Rica y Nicaragua son dos de ellos. El objetivo de este trabajo será entonces analizar por qué en Costa Rica y Nicaragua se ha trasladado una decisión como ésta del foro legislativo al foro judicial. ${ }^{4}$ En ambos casos la Constitución había prohibido o limitado de alguna manera la reelección presidencial a través de reformas constitucionales aunque de modo diferente: mientras en la Constitución costarrricense de 1949 la reelección presidencial era permitida después de un período para prohibirse totalmente tras la enmienda que reformaría la Constitución en 1969, en Nicaragua, la reforma constitucional de 1995 permitiría la reelección sólo una vez y nunca de forma consecutiva. En ambos casos estudiados, la cuestión sobre la reelección presidencial se ha trasladado al fuero judicial porque el demandante tenía como intención reelegirse. Por lo tanto, siendo consciente de que en ocasiones es difícil desligar el interés de judicializar las disputas con el interés de que la decisión sea positiva, este estudio se centrará principalmente en identificar los factores causales que influyen en que el demandante traslade una cuestión como esta a una alta instancia judicial.

Si bien las Cortes Supremas en ambos casos son muy diferentes, lo que a efectos del presente artículo nos interesa es conocer qué circunstancias hacen que las decisiones sobre este tipo de temas se trasladen a la esfera jurisdiccional en lugar de ser resueltas en la cámara legislativa.

En este sentido este artículo utilizará el diseño comparativo que se corresponde con los sistemas más diferentes de Przeworski y Tenue (1970) (o "método de la similitud" de Mill) al identificarse dos Cortes Supremas muy diferentes (una tradicionalmente activista e independiente en Costa Rica y otra débil y politizada en Nicaragua) y que sin

3 Este autor, finalmente no incluye al judicial (ni siquiera en la forma de Cortes Constitucionales) como un actor de veto dado, según sus palabras "the black box that contains decision-making by the judiciary which makes it impossible to attribute it as having a veto other policy positions" (Tsebelis, 2002: 228).

4 Este es un tema relevante y de actualidad porque, con diferentes consecuencias y procesos, podemos mencionar otros casos donde también se ha trasladado esta cuestión al foro judicial. Estamos hablando de los casos de Colombia, Argentina o Brasil, aunque las similitudes entre Costa Rica y Nicaragua hacen que se hayan seleccionado como casos paradigmáticos del fenómeno que se desea explicar. 
embargo presentan el mismo resultado: la revisión constitucional en foro jurisdiccional para permitir la reelección. Aunque este tipo de diseño sin varianza en la variable dependiente ha sido criticado por el sesgo de selección generado por la observación de casos exclusivamente "positivos" (Collier, Mahoney y Seawright, 2004; Geddes, 2003) y porque impide realizar inferencias causales ciertas (King, Keohane y Verba, 1994) algunos estudiosos de la metodología política comparada, admitiendo también sus debilidades, han reivindicado su uso (Dión, 1998; Ragin, 2000). En este sentido al comparar solamente casos positivos, el método de la similitud nos permite establecer las condiciones necesarias para un cierto fenómeno, pero no nos permite conocer las condiciones suficientes (Perez Liñán, 2007).

Aunque somos conscientes que el fundamento empírico a través de estos dos casos es bastante estrecho para un argumento general y se necesitaría testar la teoría en más casos, el desarrollo del mismo presenta una explicación que permite explorar cuáles son las condiciones necesarias que llevan a que un tema tan importante como la reelección presidencial se decida en el foro judicial en lugar del Legislativo o constituyente.

En este sentido, el modelo que se propone en este trabajo se articula en torno a dos dimensiones que explican el traslado de la cuestión de la reelección al foro judicial. La primera dimensión hace referencia al demandante (en ambos casos el afectado directo por la cuestión de la reelección), mientras que la segunda se centraría en las Cortes Supremas. Así, este artículo combinaría el análisis de los incentivos de los litigantes (examinando por qué el pretendiente lleva el asunto a la Corte) junto con los incentivos de los jueces para conocer el caso combinando así en un mismo análisis la interacción entre el "supply side" y el "demand side" en la misma línea del trabajo de Gauri y Brinks (2008).

En lo que a la primera dimensión respecta se analizarán principalmente los apoyos de la reelección en el foro legislativo y el tipo de coalición que promueva el recurso judicial. Así cuando el candidato no tenga apoyos en el Congreso debido a su fragmentación o divisiones partidistas y/o ideológicas y sin embargo pertenezca a una "coalición dominante o ascendente", éste tenderá a continuar buscando la permisibilidad de la reelección en otros foros (en este caso el judicial). Mientras que por "coalición dominante" se entiende aquella que controla el poder político, una "coalición ascendente" será la formada por actores que no han perdido el apoyo electoral o que, por el contrario, lo mantienen o incluso han crecido (Buquet, 2007: 40). Este tipo de coaliciones buscarán extender la duración del mandato incorporando la reelección presidencial particularmente "cuando la figura presidencial sea un factor esencial de ese apoyo popular" (Buquet, 2007: 37). Este tipo de coaliciones tienen dos significados en lo que a este estudio se refiere: primero, es lo que justifica que el pretendiente a la reelección crea que puede ganar y segundo le da a la Corte una suerte de justificación social o legitimidad a la hora de conocer el caso. ${ }^{5}$

5 Las coaliciones dominantes y ascendentes influyen en la creencia de que los jueces pudieran fallar a su favor: si el demandante no cree que va a ganar, no judicializa el conflicto. 
Así cuando pese a ser una coalición dominante o ascendente no obtengan los apoyos en el Legislativo, buscarán su éxito en el foro judicial (segunda dimensión de nuestro modelo) siempre que se den algunas circustancias: cuando las Cortes sean proactivas (tengan capacidad de fijar agenda) y "goal-oriented" entendiendo con esta expresión aquellas Cortes que buscan maximizar sus intereses y cuyas decisiones representan reacciones a las oportunidades y coacciones de su ambiente (Kapiszewski, 2009). Esto se debe a algo que López-Ayllón y Fix-Fierro (2003) han llamado "basic social support structures". ${ }^{6}$ Significa que las Cortes decidirán siempre que sean conscientes de que sus decisiones están "amparadas" socialmente, ya que las mismas siempre actúan "within the boundaries of both the law and the social expectations" (Handberg, Wilson, et al. 2001: 12). Aunque existe una gran dificultad a la hora de poder señalar un solo factor influyente en la toma de decisiones del Poder Judicial, ${ }^{7}$ este estudio se encuadra dentro de la reciente línea de trabajos que combinan diferentes factores que influyen en el comportamiento de los jueces. Un ejemplo de estos trabajos podemos encontrarlo en el estudio de Kapiszewski y su tesis del "tactical balancing" (2009) mediante la cual demuestra que los magistrados a la hora de decidir casos políticamente controvertidos examinan tanto el contenido como el contexto en el que deciden y la manera en la que ambas cosas interactúan definirá su comportamiento. Así ellos "equilibran" o sobrepesan tanto los factores legales, como sus preferencias políticas así como los cálculos respecto a su incidencia en la opinión pública, el poder de otros actores sobre ellos y las consecuencias políticas que puede desencadenar su resolución. ${ }^{8}$ Factores que influirán en las decisiones de los magistrados de modo diferente dependiendo de las circunstancias de cada momento. En este sentido, este estudio se centrará principalmente en la percepción que los magistrados tengan de su propio rol (también llamado "role orientations" o "cultura legal"). Dicha percepción se constituye así en un indicador fundamental para medir que las Cortes sean "proactivas". Este indicador que media entre las preferencias políticas y el comportamiento judicial (Magalhães, 2003: 264) es muy difícil de medir por lo que a efectos de este estudio se utilizarán entrevistas personales para encontrar relaciones entre la autopercepción que tengan los magistrados de su rol dentro del sistema y su comportamiento judicial.

En este sentido la reelección presidencial se decidirá en el ámbito judicial cuando el pretendiente a la reelección: (a) tenga el apoyo necesario para creer ganar la reelección y (b) controle una corte que es proactiva, pero (c) no tenga el apoyo suficiente en el Poder Legislativo para efectuar el cambio constitucional necesario.

6 Este término lo han usado los autores para explicar algunas decisiones políticas relevantes de la Corte Suprema mexicana. Otros estudios al respecto y que cita Kapiszewski (2009) serían los de Mexico (Staton, 2002), Argentina (Smulovitz y Peruzzotti, 2003) o Egipto (Moustafa, 2003).

7 Existen numerosos trabajos en los campos teóricos del "judicial behaviour" entre los que podemos mencionar a Staton (2002) y su estudio sobre cómo el apoyo público influye en el comportamiento de los magistrados o los seminales de Iaryczower et al.(2002) sobre cómo el nombramiento de jueces incluye en sus decisiones, con origen en el estudio clásico de Segal y Spaeth (2002) para la Corte Suprema de USA.

$8 \quad$ Kapiszewski indica que existen seis consideraciones que influyen en las decisiones de las Cortes Supremas y que pueden repercutir en ella en diferentes modos: “(1) justices' ideology; (2) judicial corporate or institutional interests; (3) elected branch preferences; (4) the possible economic or political consequences of the decision; (5) popular opinion regarding the case; and (6) legal considerations" $(2009,24)$. 
A estos efectos el artículo se dividirá en tres partes: en la primera se analizarán las circunstancias que llevaron a que se modificara la prohibición constitucional de la reelección en ambos países; en la segunda se analizarán las principales claves explicativas que llevaron al traslado de esta cuestión a la esfera jurisdiccional: a estos efectos se examinará la fragmentación y/o division partidista en el Congreso, la existencia de una coalición dominante o ascendente junto con un marcado carácter político de la magistratura y una composición de la misma favorable al candidato. Se concluirá planteando las bondades y los riesgos que este tipo de sentencias pueden provocar en las democracias contemporáneas.

Para desarrollar algunos de los puntos clave del artículo, en concreto los que hacen referencia al rol de los jueces se utilizarán dos tipos de fuentes: en primer lugar, entrevistas en profundidad a expertos y magistrados tanto de la Sala IV o Sala Constitucional de la Corte Suprema de Justicia de Costa Rica como de la Sala Constitucional de la Corte Suprema de Justicia de Nicaragua. En segundo lugar se utilizará la base de datos que sobre las Cortes Supremas se aplicó por la Universidad de Salamanca en 2004 dentro del proyecto "Justicia y Calidad de la Democracia en Centroamérica" (JDCA, 2004). También se ha recurrido a la fuente de datos sobre Elites Parlamentarias de América Latina (PELA) que desarrolla la Universidad de Salamanca que contiene datos sobre las opiniones, actitudes y percepciones de los diputados de todos los países de América Latina desde 1994 (ver Cuadro 1).

Cuadro 1: Bases de datos JDCA utilizadas

\begin{tabular}{|c|c|c|c|c|c|}
\hline & & $\begin{array}{c}\text { Jueces } \\
\text { Centroamérica } \\
\text { (JDCA) }\end{array}$ & & & $\begin{array}{l}\text { dores } \\
\text { Latina } \\
\text { A) }\end{array}$ \\
\hline & Fecha & $\begin{array}{c}\text { Muestra } \\
\text { (magistrados } \\
\text { Corte } \\
\text { Suprema) }\end{array}$ & $\begin{array}{l}\text { Muestra } \\
\text { (resto de } \\
\text { jueces) }\end{array}$ & Fecha & Muestra \\
\hline Costa Rica & $\begin{array}{c}(2003 y \\
2004)\end{array}$ & $\begin{array}{l}20 / 22 \\
(91 \%)\end{array}$ & $\begin{array}{c}58 / 165 \\
(35 \%)\end{array}$ & 2002 & $\begin{array}{c}51 \\
\text { entrevistas } \\
{[90 \%} \\
\text { Asamblea } \\
\text { Legislativa } \\
(2002-2006)]\end{array}$ \\
\hline Nicaragua & $\begin{array}{c}(2002 y \\
2003)\end{array}$ & $\begin{array}{c}10 / 16 \\
(62,5 \%)\end{array}$ & $\begin{array}{l}45 / 61 \\
(74 \%)\end{array}$ & 2002 & $\begin{array}{c}60 \\
\text { entrevistas } \\
{[65,22 \%} \\
\text { Asamblea } \\
\text { Nacional } \\
\text { (2002-2006)] }\end{array}$ \\
\hline
\end{tabular}




\section{LOS FALLOS REELECCIONISTAS DE LAS CORTES DE SAN JOSÉ Y MANAGUA: “CUANDO UNA GOTA DE AGUA SE PARECE MUCHO A UNA GOTA DE ACEITE"}

Cuando se le preguntó al ex presidente de Costa Rica, Óscar Arias (2006-2010), reelegido gracias a una sentencia de la Sala Constitucional de su país, por la similitud entre esta sentencia y la que ha dado luz verde a la posible reelección de Ortega, él fue tajante: "se parecen como una gota de agua y una gota de aceite":

"[...] la diferencia radica en el grado de independencia del Poder Judicial, la cual no se da en Nicaragua porque los magistrados pertenecen a los partidos politicos y responden a los partidos políticos... [De allí] no podemos compararnos. Las dos resoluciones son radicalmente distintas. En Nicaragua no hubo debate, no hubo discusión ni análisis profundo. En Nicaragua el fallo se dio 6-0 y se decidió en minutos. No tuvo el estudio que tuvo en Costa Rica, donde hubo vistas públicas y todo el mundo opinó. Tenemos instituciones muy distintas. Aquí tenemos un Poder Judicial totalmente independiente, garantizado por la Constitución" (La Nación, 4 de noviembre de 2009).

Si bien es cierto que, a diferencia del caso costarricense, en Nicaragua existieron graves irregularidades, no es menos cierto que la composición de ambas Cortes, favorables a las aspiraciones reeleccionistas del candidato, junto con la similitud de la argumentación jurídica utilizada así como el uso de un foro judicial en lugar del Legislativo confieren a ambos fallos una indudable similitud que desarrollaremos en los siguientes epígrafes.

\section{1. "La gota de agua": La sentencia con "nombre y apellidos"10}

En Costa Rica las controversias constitucionales ante la Sala Constitucional (llamada Sala IV) han convertido a dicha Sala en un prominente actor a la hora de analizar el sistema politico costarricence. ${ }^{11}$ Entre dichas decisiones judiciales el caso sobre la constitucionalidad de la reelección presidencial constituyó una de las más relevantes tanto por su incidencia política como por toda la polémica que implicó tanto el fallo como sus consecuencias en cuanto a redistribución de poderes en el país. La prohibición de la reelección inmediata y después de la enmienda de 1969 la prohibición total de reelección han caracterizado la presidencia costarricense. El debate político sobre la reelección presidencial fue intensificado desde que Óscar Arias (presidente por el Partido de Liberación NacionalPLN, durante el período 1986-1990) manifestó su intención de volver a la presidencia. ${ }^{12}$

9 Expresión utilizada por el periodista Iván Olivares para Confidencial (6-12 de diciembre de 2009).

10 Expresión utilizada por Alberto Cortés para Confidencial (6-12 de diciembre de 2009) y que hace referencia a la importancia de la figura de Óscar Arias como demandante en el caso del recurso sobre la reelección presidencial. Aunque a diferencia del caso nicaragünese, esta sentencia sí tiene efectos erga omnes.

11 Ver al respecto los estudios de Wilson (1998 y 2004), Wilson y Handberg, (1998) y Martínez-Barahona (2009).

12 El incentivó a 10 diputados del PLN que introdujeran una propuesta en la Asamblea Legislativa para anular la enmienda constitucional (Wilson, 2004: 9). 
En este sentido Arias había apoyado la propuesta de reabrir el debate en la Asamblea Legislativa como la vía correcta para revocar la prohibición de reelección, confesando que requerir a la Sala IV que interviniese para declarar la inconstitucionalidad de la prohibición podría ser considerado una "acción antidemocrática":

"La Sala Constitucional no tiene nada que ver con esto. Sería burlar a 57 diputados si uno esquiva el debate en el Parlamento. Sería una actitud antidemocrática tocar las puertas del Poder Judicial" (Declaraciones de Óscar Arias a La Nación, diciembre 2, 1999).

Así, se abrió como prioritaria la reforma constitucional en la Asamblea Legislativa mediante dos proyectos de reforma que hacían referencia respectivamente a la derogación del artículo 132 de la Constitución, el cual establecía las prohibiciones para la elección del Presidente de la República. Fue, sin embargo, el retraso legislativo en relación con esta cuestión ${ }^{13}$ junto con la existencia de una corte favorable al mismo (como explicaremos en la sección siguiente) lo que convenció al ex presidente Arias para retroceder en su posición inicial e interponer un recurso de inconstitucionalidad ante la Sala IV incluso antes de que la Asamblea Legislativa hubiese votado al respecto (Wilson, 2004: 9). No obstante, pese al revés por el primer rechazo de las dos acciones de inconstitucionalidad ante la Sala IV en 2000, ${ }^{14}$ Óscar Arias volvió a insistir en la vía judicial interponiendo tres años más tarde otro recurso ante la Sala Constitucional que esta vez decidió que la prohibición era inconstitucional. La mayoría de la Sala IV (ahora 5 de los 7 magistrados) declaró en esta ocasión que la prohibición limitaba el derecho constitucional de los individuos de buscar ser reelegidos y el derecho de los votantes para ejercer su derecho de sufragio por quien consideraran oportuno (resolución 2003-2771).

Los argumentos que se manejaron en esta segunda sentencia fueron principalmente dos: el primero y principal era que no podía hacerse una enmienda constitucional (vía reforma parcial) que perjudicara o disminuyera un derecho ya consagrado por la Constitución. El segundo consistía precisamente en confirmar que el derecho a la reelección es un derecho fundamental, de allí la lesión al procedimiento. El gran debate en torno a la segunda sentencia es que ligan el fondo (la reelección como derecho fundamental) con la forma (limitación de derechos solo puede hacerse mediante constituyente), cuando la Ley de Jurisdicción Constitucional expresamente establece que la revisión a una reforma constitucional lo es estrictamente por cuestiones de forma. ${ }^{15}$

13 Por tratarse de reformas a la Constitución, las iniciativas requieren ser aprobadas en dos debates durante una legislatura para luego recibir tres debates más en la siguiente. La Asamblea Legislativa debatió la reelección presidencial y votó mayoritariamente (32 votos sobre 13) no volver a discutirla posteriormente y archivar la cuestión (Wilson, 2004: 10).

14 La Sala IV en una decisión dividida (por 4 de los 7 magistrados que integraban la Sala en ese momento) rechazó la inconstitucionalidad por considerar que el error procedimental en la enmienda constitucional alegado en el recurso para solicitar su inconstitucionalidad no era un argumento suficiente como para remover dicha enmieda de la Constitución (Resolución 2000-7818).

15 Aunque en el primer recurso los accionantes plantearon también el argumento de la reelección como derecho fundamental, en la primera resolución la Sala Constitucional se centró en aspectos estrictamente de forma (plazo para votar un proyecto de reforma en comisión y alcance de la reforma -si esta era general o parcial-), 
El efecto inmediato de esta decisión fue permitir a los presidentes la reelección si han pasado ocho años después del fin de su primer mandato como gobernantes, lo que en términos prácticos significaba el fin del debate político sobre la candidatura de Óscar Arias para la contienda electoral de 2006. ${ }^{16}$ Este fallo redefinió y limitó también las facultades de la Asamblea Legislativa, ya que para eliminar la reforma de 1969 (que modificó el artículo 132 de la Constitución que prohibía la reelección presidencial) habría sido necesaria una reforma constitucional con una consulta preceptiva hacia la Sala IV. Sin embargo, este mecanismo no se utilizó.

Esta sentencia ha recibido críticas tanto de los propios diputados como de la opinión pública que consideran esta decisión fruto de una debilidad democrática. El profesor Volio, especialista en Derecho Constitucional, declaró a los medios de comunicación que la Sala IV había invadido las funciones de la Asamblea Legislativa:

"La Sala IV invadió funciones propias de la Asamblea Legislativa al revisar el contenido de una norma constitucional. Ahora, al determinar si una reforma es parcial o no (declaró que si se limitan los derechos fundamentales no es reforma parcial), puede anular otras reformas, pasadas o futuras. Los magistrados asumieron una función que no tenían; con esto no hay límites para la Sala IV" (La República, San José, Costa Rica - abril 8, 2003).

Lo que es indudable es que esta sentencia tuvo dos impactos evidentes en la vida política del país: primero, un reequilibrio del poder entre la Asamblea Legislativa y el Ejecutivo y segundo, de una manera más inmediata, un duro golpe a la soberanía legislativa de la Asamblea. Solís Fallas hablaba incluso de las consecuencias políticas que esta decisión podía tener en la orientación de las políticas del país: ${ }^{17}$

"[...] el tema es politico. El no tener competencias y resolver como resolvió significa un cambio radical en la vida política de este país... [...] por el hecho de que en un momento determinado en la historia de nuestro país se le permite a un expresidente ' $x$ ', don Óscar Arias [...] aspirar de nuevo [...].Entonces, esto no solamente es legitimar que los ex presidentes vuelvan o que don Óscar vuelva...esto significa un cambio... la manifestación más clara de una Sala Constitucional que opta por un modelo económico mucho más liberal".

En el mismo sentido, los profesores Gerardo Hernández y Alberto Cortés confirmarían años más tarde lo que Solís había previsto incluso antes de la reelección de Arias:

"El debate (reeleccionista en Costa Rica) se inició con la idea de Óscar Arias de volver a ser presidente, y de un grupo de poder que se fue alineando con él, en función de hacer posible la reelección" (Declaraciones de Gerardo Hernández a Confidencial: 6-12 diciembre, 2009).

incluso la Sala advirtió que sobre el fondo no tenía competencia para pronunciarse. Así, el tema de la reelección como derecho fundamental ni se menciona en el voto de mayoría.

16 Tras el fallo de la Sala IV vuelve a regir el texto del inciso 1) artículo 132 aprobado por la Constituyente de 1949: “No podrá ser elegido Presidente ni Vicepresidente de la República. 1) El que hubiera ejercido la Presidencia como titular en cualquier lapso dentro de los ocho años anteriores al período para cuyo ejercicio se verifique la elección y el vicepresidente o quien la hubiera servido durante la mayor parte del período que corresponda".

17 Entrevista realizada al Dr. Solís Fallas (San José de Costa Rica, 14 de septiembre de 2005). 
"[...] la razón para proponer la candidatura de Arias respondía a una apuesta que estaban haciendo grupos de poder muy importantes para garantizar que en la elección del 2006, Óscar Arias pudiera ganar la presidencia[...] se querían impulsar un tipo de reformas politicas y económicas incluyendo la aprobación del Tratado de Libre Comercio con Estados Unidos...y la única figura en ese momento que podría garantizar a ese sector el triunfo electoral y hacer las reformas era Óscar Arias" (Declaraciones de Alberto Cortés a Confidencial: 6-12 diciembre, 2009).

Pero el problema político más grave vendría si se considerase esta decisión de la Sala IV como un precedente que podría permitir en el futuro evitar la reforma constitucional. Como nos indicaba Solís Fallas:

"[...] la presión para privatizar, para prescindir de lo público etc., etc...es tremenda...y eso se manifiesta de una manera muy clara en la justicia constitucional...y este fallo es una consolidación de un modelo que se quiere implementar en nuestro país sin la necesidad de modificar la Constitución política".

Contra estas críticas, algunos magistrados de la Sala IV consideran que la misma actuó debido a la inactividad de la Asamblea Legislativa. En este sentido la magistrada de la Sala IV Ana Virginia Calzada nos declaraba: ${ }^{18}$

"[... la Asamblea Legislativa no quiso resolverlo por otro lado y nos lo trasladó a nosotros... es un típico caso en el que la Asamblea Legislativa debió haber convocado a una constituyente y reformar la decisión... pero bueno...no se hizo y nos tocó a nosotros hacerlo".

\section{2. "La gota de aceite": La sentencia que estaba "escrita en piedra"19}

Del mismo modo que haría el ex presidente Arias, el actual presidente de Nicaragua Daniel Ortega (2001-2012) iniciaría formalmente la búsqueda de su reelección presidencial a través de la Corte Suprema de Justicia (CSJ) y no mediante una reforma constitucional en la Asamblea Nacional.

En el caso nicaragüense, al igual que el de su país vecino, Ortega buscó en todo momento los 56 votos en la Asamblea Nacional, para aprobar la reforma, pero la imposiblidad de poder obtener esa votación así como contar con una Corte proactiva y a su favor, hizo que recurriera ante el poder Judicial. Así, de modo similar a lo que sucedió en Costa Rica, la Sala Constitucional de la Corte Suprema de Justicia, gracias a la mayoría en este caso de seis magistrados sandinistas, declaró inaplicable el art. 147 de la Constitución que prohíbe a los presidentes, vicepresidentes, alcaldes y vicealcaldes ser candidatos en elecciones consecutivas al mismo cargo, aclarando en todo momento que la decisión tiene efectos inter partes, es decir, tiene efectos sólo para el caso concreto que se solicita: de 2005).

19 Declaraciones de Ortega tras la sentencia "reeleccionista": "Como decían los magistrados, ésta ya es una sentencia aprobada en piedra, es inapelable, y esto es importante que lo tengan claro los oligarcas vendepatria" (El Nuevo Diario, 26 de octubre de 2009). 
sólo afecta al caso de la reelección del presidente Ortega y los 109 alcaldes sandinistas que presentan el amparo. ${ }^{20} \mathrm{El}$ argumento que se esgrimió en la decisión judicial hacía referencia a que las disposiciones constitucionales contenidas en los artículos 147 y 178 Constitución (reformadas por el Constituyente Derivado mediante el artículo 13 de la Ley N 192 el 4 de julio de 1995) creaban "una discriminación e interdicción electoral para Presidente y Vicepresidente, Alcalde y Vicealcalde". Los seis magistrados del FSLN alegaron que "el poder Constituyente Derivado" (los legisladores que reformaron la Constitución en 1995), no podían estar sobre "el poder constituyente originario", en referencia a los legisladores de $1987 .^{21}$

Sin embargo, a diferencia del caso costarricense, en Nicaragua las irregularidades tanto en la conformación de la Sala Constitucional como en el recurso utilizado para dirimir este tipo de controversias han hecho que esta decisión sea mucho más que controvertida. ${ }^{22}$ Una de las principales irregularidades procedimentales se debió a la violación de los procedimientos establecidos en la Ley Orgánica del Poder Judicial para la integración de la Sala Constitucional en la que estuvieron ausentes los magistrados liberales (que fueron sustituidos por los suplentes de todos los magistrados sandinistas). Cuando se le preguntó por esta cuestión al presidente de la Sala Constitucional, el magistrado sandinista Francisco Rosales, indicó que si bien convocó a Sala Constitucional a los magistrados liberales que conforman dicha Sala, Sergio Cuarezma, Iván Escobar Fornos y Damisis Sirias, éstos no se presentaron y tuvieron que llenarse sus lugares con los magistrados sandinistas Centeno, Cuadra y Méndez (La Prensa, 19 de octubre de 2009). Después de la integración irregular de la Sala, el fallo se produjo en cuestión de horas fallando a favor del recurso de amparo.

Todas estas irregularidades fueron señaladas por los magistrados liberales en un comunicado el 29 de octubre de 2009 en el que se pronunciaban contra la sentencia "reeleccionista". En dicho comunicado, firmado por el presidente del Poder Judicial, magistrado Manuel Martínez, así como por los magistrados Damisis Sirias, Sergio Cuarezma, Antonio Alemán, Iván Escobar Fornos, Edgard Navas y Gabriel Rivera, se indica que la sentencia es ilegal, nula e inexistente la integración de la Sala Constitucional

20 Mientras la sentencia de la Sala Constitucional no sea ratificada por la Corte Plena de la Corte Suprema de Justicia, solo beneficiará a Ortega y a los 109 alcaldes sandinistas.

21 Continúa la sentencia diciendo que esta antinomia se debe a que colisionan "con respecto a los siguientes Principios Constitucionales": 1.- El Principio Fundamental y Supremo de la Igualdad Incondicional de TODOS los nicaragüenses EN y ANTE LA LEY; 2.- El Principio de Soberanía y Autodeterminación Nacional inextricablemente vinculado al Principio Constitucional de Prelación de los Intereses Supremos de la Nación, y de la obligación de ejercer la función pública a favor de los intereses del Pueblo; así como del Derecho al Sufragio Electoral de los nicaragüenses: Derecho a Elegir y ser Elegido; Derecho de ejercer los derechos políticos, sin más limitaciones que por razones de edad y por suspensión de los Derechos ciudadanos mediante sentencia penal o interdicción civil" (Sentencia No 504 de la Corte Suprema de Justicia.- Sala de lo Constitucional.- Managua, 19 de octubre de 2009). El énfasis es el que aparece en la misma sentencia.

22 El régimen jurídico nicaragüense es suficientemente claro en el artículo 6 de la Ley de Amparo y en el artículo 187 constitucional que establecen que la inconstitucionalidad sólo cabe contra leyes de rango inferior a la Constitución. 
que hizo el magistrado sandinista Francisco Rosales, para fallar a favor de Ortega. ${ }^{23}$ Incluso van más lejos diciendo que haya sido o no integrada legalmente, la Corte "no tiene potestad de semejante atentado contra el orden Constitucional" ya que "admiten un amparo de manera ilegal, puesto que se recurrió contra un acto presunto y no en contra de un acto consumado como lo establece la Ley de Amparo; amén de que no hay amparo en contra de la Constitución Política". Ellos finalizan el comunicado señalando los peligros de dar facultades legislativas a la Corte.

Ni el recurso de nulidad, presentado por los diputados del Partido Liberal Constitucionalista (PLC) en contra de la sentencia, ${ }^{24}$ ni la iniciativa de ley para anular la sentencia fundamentada en el hecho que la Corte no puede atribuirse funciones en la elaboración y anulación de las leyes porque son funciones de la Asamblea Nacional, han prosperado. ${ }^{25}$

\section{EN BUSCA DEL “ATAJO” JUDICIAL}

Teniendo en cuenta las diferencias entre los dos casos en cuestión, que se han indicado en la sección precedente, este epígrafe tratará de generalizar y reflexionar acerca de las circunstancias que han llevado a que una decisión de estas características se haya trasladado en ambos casos a la esfera jurisdiccional.

A efectos de nuestro análisis empírico se tratará de vincular el traslado de la decisión sobre la reelección presidencial a la esfera judicial a dos variables institucionales fundamentales: la ausencia de mayorías legislativas por parte de la coalición dominante o ascendente y unas Cortes Supremas proactivas y "amigables" al demandante en la solicitud de reelección.

\subsection{Costa Rica: Donde las decisiones se toman por "políticos con togas"}

\subsubsection{Fragmentación parlamentaria y coalición ascendente}

Dos partidos políticos (el socialdemócrata, Partido Liberación Nacional -PLN, y el democratacristiano, Partido Unidad Social Cristiana -PUSC) controlaron hasta las elecciones de 2006 casi el 90\% del voto presidencial y se han alternado en el control de la Asamblea Legislativa, el poder más importante de acuerdo con la Constitución de 1949. Sin embargo, desde 1990 la creciente tendencia a la fragmentación parlamentaria

23 En este sentido el comunicado indica que "no se convocó de manera legal y transparente a los magistrados liberales Sergio Cuarezma, Iván Escobar Fornos y Gabriel Rivera y que fue hasta que éstos se retiraron de la CSJ que les pusieron la convocatoria debajo de las puertas de sus despachos" (La Prensa, 29 de octubre de 2009). A este recurso no se le dio trámite por considerarlo "improcedente". En este sentido el magistrado sandinista Francisco Rosales, presidente de la Sala Constitucional de la Corte Suprema de Justicia (CSJ), indicó que frente a la sentencia sólo cabe recurso de aclaración que debió ser presentado por las partes en el período de 24 horas después de notificada la sentencia. El magistrado sandinista Rafael Solís, vicepresidente del Poder Judicial y también miembro de la Sala Constitucional de la Corte, informó que el recurso también se rechazó porque los diputados del PLC no son parte del recurso de amparo ("Sandinistas botan recurso de nulidad contra sentencia 'reeleccionista'", en La Prensa, 22 de octubre de 2009).

25 "Diputado de ALN impide avance del proyecto de Ley contra la reelección", en La Prensa, 28 de octubre de 2009. 
en Costa Rica ha convertido a la Sala IV en un importante órgano estratégico para los partidos de oposición cuando quieren retrasar o bloquear iniciativas legislativas. ${ }^{26}$ Como se puede ver en Cuadro 2, no ha habido ningún partido que haya tenido el control de la Asamblea Legislativa desde 1994.

Es más, ni en el período en el que se presentó el primer recurso ante la Sala IV (19982002) ni en el que presentó el segundo (2002-2006), el PLN, partido de Óscar Arias, tenía la mayoría en la Asamblea. Incluso los medios de comunicación se hicieron eco en todo momento del escaso ambiente en la Asamblea Legislativa para impulsar los proyectos "reeleccionistas". Así, durante el período 1998-2002, tanto el jefe de la bancada del Partido Liberación Nacional (PLN), Daniel Gallardo, como su contraparte del Partido Unidad Social Cristiana (PUSC), Eliseo Vargas, comentaron que dicho proyecto de reforma no era prioritario en el Congreso.

"Sinceramente, este no es un buen momento para hablar de reelección presidencial. En mi fracción no sé quienes puedan apoyar esta iniciativa [...] es un tema del cual ni se habla" (Declaraciones de Gallardo a La Nación, 2 de diciembre de 1999).

Cuadro 2: Controles entre Ejecutivo y Legislativo (1982-2010)

\begin{tabular}{llllll}
\hline & \multicolumn{1}{c}{$\begin{array}{c}\text { Control del } \\
\text { Ejecutivo/ } \\
\text { Presidente }\end{array}$} & $\begin{array}{c}\text { Control } \\
\text { Legislativo }\end{array}$ & $\begin{array}{c}\text { Porcentaje } \\
\text { diputados } \\
\text { controlados } \\
\text { por Presidente }\end{array}$ & $\begin{array}{c}\text { No efectivo }_{\text {de partidos }} \\
(\text { NEP) }\end{array}$ & $\begin{array}{c}\text { Índice de } \\
\text { Fragmentación } \\
(\mathrm{F})\end{array}$ \\
\hline $1982-1986$ & PLN/Luis A. Monge & PLN & $58 \%$ & 2,27 & 0,56 \\
$1986-1990$ & PLN/Óscar Arias & PLN & $51 \%$ & 2,21 & 0,55 \\
$1990-1994$ & PUSC/Rafael A. Calderón & PUSC & $51 \%$ & 2,21 & 0,55 \\
$1994-1998$ & PLN/José M Figueres & Minoría & $49 \%$ & 2,29 & 0,56 \\
$1998-2002$ & PUSC/M. A. Rodríguez & Minoría & $47 \%$ & 2,55 & 0,61 \\
$2002-2006$ & PUSC/Abel Pacheco & Minoría & $33 \%$ & 4,12 & 0,76 \\
$2006-2010$ & PLN/Óscar Arias & Minoría & $43 \%$ & 3,32 & 0,70 \\
\hline
\end{tabular}

Fuente: Elaboración propia basada en datos del Tribunal Supremo de Elecciones.

Así las cosas, no debe de extrañarnos que Óscar Arias, ante la falta de apoyos en el Legislativo, decidiera recurrir a la Sala IV como órgano para dirimir la controversia de la reelección presidencial. Aunque la Sala IV falló de forma diferente en 2000 respecto al 2003, en ambos períodos el PLN se configuraba ya como una coalición ascendente como confirmaban todas las encuestas. ${ }^{27}$ Que estas circunstancias influyeron en los magistrados a aceptar de nuevo en el 2003 conocer el caso de la reelección es algo que demostraremos en la siguiente sección.

26 Al respecto ver Martínez-Barahona (2009).

27 Los medios de comunicación ya meses antes de la sentencia se hacían eco de la inmensa popularidad de Óscar Arias: “Respaldo popular: Óscar Arias tiene gran apoyo según las encuestas” (en La Nación, 5 de abril del 2003). 


\subsubsection{Una Sala Constitucional favorable al demandante}

Si bien el cambio en la composición de la Sala IV es uno de los elementos más significativos a la hora de señalar por qué hubo una variación de fallo entre la sentencia del 2000 y la del 2003, no hay que olvidar que el demandante (Óscar Arias) en ambas ocasiones creía tenerla controlada (ver apoyo partidista en Cuadros 3 y 4). En este sentido, fueron muy polémicas las declaraciones que Guido Sáenz, ex ministro de Cultura y miembro del PLN hizo en su libro autobiográfico, a propósito de las sentencias del 2000:

"Lo llamé (refiriéndose a Óscar Arias) en cuanto me enteré de la catástrofe (el fallo negativo de la Sala Constitucional), y me dijo: Guido, yo estaba ciento por ciento seguro que me pasaban la reforma. Tenía la promesa de cuatro magistrados, uno me traicionó" (Fernández Sáenz 2003: 361).

Ante estas polémicas declaraciones que destaparon posibles presiones a los magistrados a la hora de decidir sobre este caso, Fernández Sáenz fue llamado por la Asamblea para que rindiera cuentas de esta afirmación, pero la "investigación" no prosperó, ya que Fernández Sáenz justificó esa frase como "licencia literaria".

Óscar Arias perseveró en su intento de dirimir la controversia constitucional sobre la reelección presidencial en foro jurisdiccional consciente de que su coalición ascendente y la proactividad de la Sala IV le serían favorables. En este sentido hay que destacar que aunque nuestra hipótesis no se centre en el éxito del recurso, no es menos cierto que el demandante jamás recurriría a este foro si no fuera consciente de que el resultado podría serle favorable. En 2003, los cambios en la composición de la Corte incentivarían al demandante a presentar otro recurso. En este sentido, en la nueva Sala IV la presidencia había cambiado del magistrado Luis Paulino Mora (quien voto contra la reelección en las dos ocasiones) al magistrado Luis Fernando Solano (quien voto a favor) y lo que es más importante, dos de los magistrados que votaron contra la reelección se habían retirado de la Corte y fueron reemplazados por magistrados que finalmente votarían a favor. ${ }^{28}$ Mientras muchos juristas ven en esta variación de la opinión de los jueces una señal de que los miembros de la Corte no han articulado y defendido un argumento jurídico homogéneo necesario para asegurar el estado de derecho (rule of law), este comportamiento es aceptado por los politólogos como clara evidencia de que las Cortes Supremas son también un órgano político y como tal conducido por las preferencias políticas de sus miembros (Bybee, 2000).

Pese a existir un sistema que garantiza la independencia en la selección de magistrados, ${ }^{29}$ es indudable que el cambio de composición de la Sala modificó la correlación de fuerzas que propiciaría una Sala más favorable a la reelección, lo que hizo posible la modificación

En este sentido el Diputado por el PLN Legislador Guido Miranda declaró: "Es una barbaridad que la Sala IV, que rechazó la reelección hace un tiempo, ahora la acepte porque cambiaron tres de sus magistrados" ("Lluvia de críticas a la Sala IV" en La Nación, 6 abril de 2003).

29 Esto se debe principalmente a tres factores: Los magistrados son elegidos por un período de ocho años renovable (mientras los diputados son elegidos por un período de cuatro años sin posibilidad de reelección), lo que evita lealtades en su nombramiento. En segundo lugar, los magistrados son elegidos por 2/3 de la Asamblea Legislativa, lo que implica un gran consenso en la elección de los magistrados. En último lugar, se mantienen las garantías en el cargo, ya que la reelección de los magistrados es automática salvo que tengan un voto negativo de los $2 / 3$ de la Asamblea (más de 38 votos). 
del fallo. Así, los hechos nos indican que precisamente fueron los magistrados Luis Paulino Mora y Carlos Arguedas los dos únicos magistrados que quedaron de los cuatro que el 5 de septiembre de 2000 conformaron el bloque mayoritario que rechazó dos acciones presentadas contra el procedimiento que siguió la Asamblea Legislativa para prohibir la reelección de 1969 (ver Cuadro 3 y Cuadro 4). Es más, hay incluso quien señala que "el caso fructificó en la tercera, una vez que se dio un cambio en la conformación de la Corte Constitucional, cuando ingresó un magistrado que previamente había expresado su opinión a favor de la reelección" (Declaraciones de Gerardo Hernández para Confidencial: 6-12 diciembre).

Cuadro 3: Composición de la Sala IV durante la sentencia del 2000

\begin{tabular}{llcc}
\hline \multicolumn{1}{c}{ Nombre } & \multicolumn{1}{c}{ Período } & $\begin{array}{c}\text { Principal apoyo } \\
\text { partidista }\end{array}$ & $\begin{array}{c}\text { Decisión Reelección } \\
\text { (Óscar Arias) }\end{array}$ \\
\hline Piza Escalante & $(1989-2000)$ & PUSC & No \\
Solano Carrera & $(1989-2008)$ & PLN & Sí \\
Mora Mora & $(1989$-actualidad) & PLN & No \\
Arguedas Ramírez & $(1992-2004)$ & PLN & No \\
Sancho González & $(1990-2006)$ & PUSC & No \\
Calzada Miranda & $(1993$-actualidad) & PUSC & Sí \\
Vargas Benavides & $(1997$-actualidad) & PLN & Sí \\
\hline
\end{tabular}

Cuadro 4: Composición de la Sala IV durante la sentencia del 2003

\begin{tabular}{|c|c|c|c|c|}
\hline Nombre & Período & $\begin{array}{l}\text { Número de votos } \\
\text { (nombramiento/ } \\
\text { reelecciones) }\end{array}$ & $\begin{array}{l}\text { Principal } \\
\text { apoyo } \\
\text { partidista }\end{array}$ & $\begin{array}{c}\text { Decisión } \\
\text { Reelección } \\
\text { (Óscar Arias) }\end{array}$ \\
\hline Solano Carrera & (1989-2008) & $\begin{array}{l}44 \text { en } 1989 \\
36 \text { en } 1997 \\
18 \text { en } 2005 \\
47 \text { en } 1989\end{array}$ & PLN & Sí \\
\hline Mora Mora & (1989-actualidad) & $\begin{array}{l}36 \text { en } 1997 \\
32 \text { en } 2005\end{array}$ & PLN & No \\
\hline Arguedas Ramírez & (1992-2004) & $\begin{array}{l}45 \text { en } 1992 \\
36 \text { en } 2000\end{array}$ & PLN & No \\
\hline Calzada Miranda & (1993-actualidad) & $\begin{array}{l}39 \text { en } 1993 \\
17 \text { en } 2001 \\
2009\left(^{*}\right)\end{array}$ & PUSC & Sí \\
\hline Vargas Benavides & (1997-actualidad) & $\begin{array}{l}46 \text { en } 1996 \\
2005\left(^{*}\right)\end{array}$ & PLN & Sí \\
\hline Jinesta Lobo & (2002-actualidad) & 39 & Consenso & Sí \\
\hline Armijo Sancho & (2002-actualidad) & 38 & Consenso & Sí \\
\hline
\end{tabular}

(*) Magistrado reelegido automáticamente porque terminó su mandato sin el voto sobre su reelección de la Asamblea Legislativa. (Resolución n. A-11443 del Ejecutivo. Acuerdo 5005 12/8/99 y No 5005 12/8/05)

Fuente: Elaboración propia a partir de Rodríguez Cordero $(2002,51)$ y datos proporcionados por Gabriela Carro (Protocolo y Relaciones Públicas. Corte Constitucional Costa Rica), Danilo González (Departamento de Archivo. Asamblea Legislativa de Costa Rica), Hugo Picado y Diego Brenes. 
Aunque el rumor del reparto de cuotas en la alta magistratura fruto de la "agenda política sumergida" es algo que no se ha podido demostrar, es evidente que la ideología y los valores son determinantes a la hora de elegir un magistrado y han podido influir en la elección de los nuevos magistrados que votarían a favor de la reelección presidencial. Esto se sostiene también por el hecho que los magistrados que componían la Sala IV durante estos recursos eran elegidos por 2/3 de la Asamblea Legislativa (art. 163 Constitución reformado por la Ley 8.365), lo que implicaba un gran consenso en la elección de los magistrados. Este sistema requería compromisos entre los diferentes partidos de la Asamblea Legislativa, ya que es imposible para un partido político elegir un magistrado sin el consenso del resto. Esta clase de votación garantizaba que ningún magistrado fuera elegido con una mayoría escasa y también evitaba que un partido pudiera influir directamente en la Corte Suprema. Aunque en la actualidad existe un nuevo procedimiento a través de un concurso público, los nombramientos de los magistrados que decidieron sobre el caso Óscar Arias siguieron el procedimiento descrito. ${ }^{30}$ Así Óscar Arias pese a no disponer de mayoría podía estar seguro de que parte de la Sala le era afín. En este sentido, el actual magistrado de la Sala IV, Fernando Cruz expresaba "no sería realista pretender que los magistrados constitucionales que son la judicatura más politizada no pase por el tamiz de una valoración política": ${ }^{31}$

"Se decía en la agenda política sumergida que los dos partidos mayoritarios estaban puestos de acuerdo de que cada vacante iban repartiéndoles uno a uno: ahora te toca a ti, ahora a mí. Lo cual significa que había un direccionamiento político de quienes son los electos".

Incluso iba más lejos:

“(...) no desconozco que el tema de la designación de los magistrados tiene que ver con una profundización de los que los eligen para saber cuáles son los valores, cuáles son las pautas y cuáles son las orientaciones ideológicas de ese magistrado especialmente de la pequeña política...cuáles son, digamos, sus simpatías y eso puede incidir en la forma en que resuelve.... (...) ¿Y por qué se elige con determinada orientación? Bueno, porque se quiere que a la hora de resolver, aplique valores...puede ser que sea muy gubernamental, puede ser que sea un convencido de que hay que desarmar el estado social y que hay que privatizar, etc., y todo eso va a incidir en la forma en que resuelve, claro".

El profesor Solís Fallas va incluso más lejos cuando dice:

"...pero indudablemente que a nivel político sin que uno pueda demostrarlo tuvo presiones... hay gente que llega a afirmar que algunos magistrados fueron nombrados previa consulta de cuales eran sus opiniones en relación a esos temas".

30 El nuevo procedimiento se efectúa a través de un concurso público llevado a cabo por la "Comisión de nombramientos de la Asamblea Legislativa". Así se impone comos nuevos requisitos en la elección de los magistrados los siguientes: estudios relacionados con el cargo (23 puntos), experiencia relativa al cargo (33 puntos), publicaciones relativas al cargo (15 puntos), idiomas ( 2 puntos), premios (2 puntos) y entrevista personal (25 puntos).

31 Entrevista realizada al magistrado de la Sala IV (San José de Costa Rica, 2 de septiembre de 2005). 
Así, no sólo la selección de nuevos magistrados con nuevas orientaciones políticas pudo influir en el cambio del fallo de la Sala, también las expectativas de los mismos magistrados frente a su futura reelección pudo haber influido en su voto estratégico. ${ }^{32}$ En este sentido, el Cuadro 4 nos indica cómo el magistrado Fernando Solano Carrera, el único magistrado que votó a favor de la reelección presidencial y que debía ser reelegido por la Asamblea Legislativa en la que el PLN aún tenía una posición minoritaria (20022006), recibió duras críticas en su reelección (sólo 18 votos apoyaron su reelección). ${ }^{33}$ Esta reducción del apoyo legislativo o "castigo" fue señalada también por los medios de comunicación. ${ }^{34}$ De este modo, es interesante señalar cómo el hecho de que existiera una coalición política ascendente (en este caso el PLN) podría haber influido en el hecho de que los magistrados recién electos (Jinesta Lobo o Armijo Sancho) votaran estratégica y positivamente a favor del demandante Óscar Arias pensando en que su reelección dependería de una Asamblea Legislativa que les sería favorable en caso de que se posicionaran a favor de la reelección del líder del PLN.

Indudablemente tampoco se puede negar que la insistente actividad de los medios de comunicación indicando que la ciudadanía votaría mayoritariamente a favor de Óscar Arias en caso de que se le permitiera la reelección, no tuviera una incidencia en que los magistrados volvieran a admitir el recurso a trámite en 2003 y que más tarde sentenciara a su favor. ${ }^{35}$ En este sentido, hay que indicar que los magistrados costarricenses se manifiestan especialmente vulnerables a la hora de indicar cómo son los medios de comunicación, los grupos que más injerencia tienen en sus decisiones. ${ }^{36}$ Algo que también apuntaba el profesor Solís Fallas:

"Evidentemente es una Sala que se dejó como mínimo impresionar por unas encuestas de opinión que favorecían de una manera muy positiva a uno de los que hoy está aspirando a la presidencia de la República y que va a ser presidente de la República -d. Óscar Arias. [...] Evidentemente las encuestas de opinión pública crean un estado de opinión que facilita al órgano constitucional legitimar más tarde una decisión. Es que había un 70\%, un 80\% a favor de un determinado cambio. Eso le da mucha seguridad, mucha legitimación a cualquier sentencia".

Los magistrados de la Sala IV tienen que defender su reelección ante la Asamblea Nacional con el fin de aspirar a la renovación de su período. Dependiendo así de los votos a favor o en contra de su reelección, un magistrado puede conocer si su labor fue aprobada o no. Esto supone un mecanismo efectivo de horizontal accountability o rendición de cuentas "horizontal".

33 Legisladores Federico Malavassi, José Miguel Corrales y Rodrigo Carazo «pasaron factura» al magistrado Solano por su posición en el caso de la reelección presidencial (La Nación, 27 de septiembre 2005).

34 En esa reelección de los magistrados, La Nación titulaba "Legisladores castigan a magistrados de Sala IV" 27 de septiembre de 2005. Solano fue reelegido con 32 votos negativos.

35 Así, en la última encuesta hecha por la firma Unimer en enero de 2003, se indicaba que Óscar Arias obtendría el 86,9 por ciento de apoyo en caso de que se pudiera presentar en la próxima contienda electoral. En el camino por la reelección, Arias organizó una consulta popular en el escrutinio interno del PLN el 12 de marzo del 2000. Ese día, más de 100.000 personas votaron a favor de la reelección, es decir, el 88 por ciento de los participantes en la consulta.

36 En este sentido a la pregunta ( $\left.\mathrm{N}^{\circ} 13\right)$ : "Indique el grado de injerencia en las decisiones de los jueces de los siguientes grupos o instituciones (...)", un $26,6 \%$ de los magistrados indica que son los mass media quienes influyen de modo considerable en sus decisiones. Es el único grupo del que destacan su influencia. Fuente: JDCA (2004). 
En este sentido en 2003 las circunstancias políticas habían cambiado e influyeron de manera relevante en la decisión de la Sala, que se sintió legitimada y "amparada" socialmente en su fallo frente a la posibilidad de represalia o respuesta por parte del resto de poderes. Una Sala que es consciente de su gran poder politico como árbitro dentro del sistema político costarricense y de las grandes expectativas públicas hacia ellos. Así, los magistrados costarricenses y proactivos se presentan como extremadamente sensibles a lo que ocurre en su entorno. ${ }^{37}$ Como el magistrado Luis Paulino Mora señala: ${ }^{38}$

"[...] ahora los jueces también tenemos actividad política...no actividad de partido, pero sí actividad política. Aunque a la mayoría de los jueces nos da mucha vergüenza aceptarlo

[...] nos hemos acostumbrado a decir que los políticos nada que ver con nosotros...pero eso porque no sabemos qué es hacer politica".

Los magistrados de la Sala IV aceptaron este nuevo mandato y utilizaron sin ninguna timidez las amplias competencias formales que la elite nacional les había dado. Esto sumado a la gran aceptación que su papel tiene gracias a que su independencia pudo haber contribuido a que Óscar Arias la eligiera como el mejor foro para defender sus intereses. ${ }^{39}$

\subsection{Nicaragua: ¿para qué controlar la Asamblea si se controla la corte?}

\subsubsection{Asamblea dividida y coalición dominante}

En esta sección se analiza cómo la fragmentación parlamentaria y la complejidad de negociación en la Asamblea nicaragüense ha influido en el hecho de que se trasladen las cuestiones políticas -entre ellas la reelección presidencial- a la esfera judicial convirtiendo así a la Corte Suprema en un actor estratégico a la hora de resolver los problemas políticos.

Observando el Cuadro 5 podemos ver cómo, al igual que en el caso costarricense hasta la década de los 90 , existe un estable bipartidismo entre liberales y sandinistas que se reparten desde las elecciones de 1996 el 90\% del voto. Aunque no vamos a entrar aquí a desarrollar cómo se ha consolidado este bipartidismo y cómo el Pacto llevado a cabo en el 2000 entre el PLC y el FSLN ha afectado profundamente el sistema de partidos, ${ }^{40}$ sí es relevante señalar la complejidad que existe para llegar a acuerdos entre los dos grandes partidos agravada por el hecho de la gran distancia ideológica que existe entre los mismos (ver Cuadro 6). Así, la fortaleza de la oposición en Nicaragua junto con su diferenciación ideologica hacen que se incremente el poder del Judicial como "árbitro" en el juego político. De hecho, el actual Legislativo convierte a la Corte Suprema en el único árbitro posible.

37 No voy a profundizar en el análisis de su rol proactivo dentro del sistema político costarricense, ya que hay abundante literatura escrita sobre el mismo. Ver al respecto los trabajos de Wilson o de Martínez-Barahona. Entrevista realizada al magistrado de la Sala IV Luis Paulino Mora (San José de Costa Rica, agosto 2003).

39 Es importante indicar aquí cómo la legitimidad judicial depende en buena medida del mito de la neutralidad e independencia de la magistratura (Shapiro, 2002: 15).

$40 \quad$ Ver al respecto Close (2003), Dye (2004) y Close y Marti (2009). 
Cuadro 5: Controles entre Ejecutivo y Legislativo en Nicaragua (1985-2006)

\begin{tabular}{lllccc}
\hline & \multicolumn{1}{c}{$\begin{array}{c}\text { Control Ejecutivo control/ } \\
\text { Presidente }\end{array}$} & $\begin{array}{c}\text { Control } \\
\text { Legislativo }\end{array}$ & $\begin{array}{c}\text { Porcentaje } \\
\text { diputados } \\
\text { controlados } \\
\text { por Presidente }\end{array}$ & NEP & F \\
\hline $1985-1990$ & FSLN/Daniel Ortega & FSLN & $61 \%$ & 1,86 & 0,46 \\
$1990-1997$ & UNO/Violeta Barrios de Chamorro & UNO & $55 \%$ & 2,05 & 0,51 \\
$1997-2002$ & AL/ Arnoldo Alemán & Minoría & $47 \%$ & 2,52 & 0,60 \\
$2002-2006$ & PLC/Enrique Bolaños & PLC & $51 \%$ & 2,08 & 0,52 \\
$2006-2010$ & FSLN/Daniel Ortega & Minoría & $41 \%$ & 3,3 & 0,7 \\
\hline
\end{tabular}

Fuente: elaboración propia basada en Consejo Supremo Electoral.

Cuadro 6: Oposición en Nicaragua (1996-2006)

\begin{tabular}{lcccc}
\hline $\begin{array}{c}\text { Período } \\
\text { Legislativo }\end{array}$ & $\begin{array}{c}\text { Autoubicación } \\
\text { ideológica del } \\
\text { gobierno }\end{array}$ & $\begin{array}{c}\text { Autoubicación } \\
\text { ideológica de } \\
\text { mayor partido } \\
\text { de la oposición }\end{array}$ & $\begin{array}{c}\text { Mayor partido } \\
\text { de la oposición } \\
\text { (\% escaños) }\end{array}$ & $\begin{array}{c}\text { Total de la } \\
\text { oposición* } \\
\text { (\% escaños) }\end{array}$ \\
\hline 1996-2001 & AL $(6,69)$ & FSLN $(2,63)$ & 39,78 & 52,68 \\
$2002-2006$ & PLC $(7,00)$ & FSLN $(1,83)$ & 46,74 & 48,91 \\
\hline
\end{tabular}

${ }^{*}$ ) El total de la oposición fue calculado como el porcentaje de partidos diferentes a aquel que controla el Ejecutivo.

Fuente: Elaboración propia.

Daniel Ortega, al igual que Óscar Arias, no tenía control sobre la Asamblea para proponer la reforma constitucional que requiere de 56 votos en la Asamblea Nacional. ${ }^{41}$ Sin embargo, esto no representaba ningún problema, ya que tenía asegurado su triunfo a través de un órgano que se ha convertido desde hace años en objeto de acuerdos y pactos para poder situar a sus simpatizantes entre sus filas: la Corte Suprema de Justicia. Una Corte que indudablemente ha fallado a favor de Ortega en un momento en el que las últimas encuestas lo presentan de nuevo como la única opción viable para las próximas elecciones de $2012{ }^{42}$

\subsubsection{Alta "disciplina partidista"... en la Corte Suprema}

No se puede examinar el caso de Nicaragua sin hacer referencia a la Constitución de 1995 y a las reformas constitucionales tras el acuerdo político denominado por los

41 Aunque en realidad la bancada oficial del Frente Sandinista no objetó en ningún momento el doble candado a la reelección presidencial introducido en el artículo 147 en la reforma constitucional de 1995 como se puede constatar en los libros del diario debate de la primera y segunda legislaturas de esa época.

42 En el mismo período en el que se sentenció el caso, las encuestas daban un nivel de aprobación del 32\% al gobierno del presidente Ortega, que aunque pudiera parecer insuficiente, es superior al recibido por la oposición (Encuesta Nacional realizada entre el 27 de noviembre y el 5 de diciembre entre 1.600 personas con un margen de confianza del 95,5\% (Confidencial, 20 de diciembre-10 enero). 
nicaragüenses "el Pacto", alcanzado por primera vez en 2000 entre los principales líderes del país: el liberal Arnoldo Alemán y el sandinista Daniel Ortega. Este acuerdo, que surgió en parte como reacción a la reforma constitucional de 1995 (la distribución de poder dentro de la Asamblea Nacional no correspondía con aquella en el resto de instituciones políticas, incluida la Corte Suprema), configura de facto un reparto de las principales instituciones del país. Así, la presidencia y hasta la organización de las cuatro salas que componen la Corte Suprema de Justicia obedecen a los intereses de uno u otro partido, comprometiendo así la resolución de casos específicos en el que pudieran verse implicados. ${ }^{43}$ Así señalaba el entonces magistrado Guillermo Vargas Sandino: ${ }^{44}$

"[...] en su momento cuando en el año 95 se estaban haciendo las reformas constitucionales, yo era presidente de la CSJ y yo hablé con el Presidente de la República, el Dr. Alemán...y le dije que esas reformas podrían ser terriblemente perjudiciales para el Poder Judicial, que iban a ser muy perjudiciales porque lo que iban a hacer era politizarlo más... y entonces me dijo que 'no, que todo estaba arreglado' ... y resulta que lo que menos se hizo fue arreglarlo...buscaron cómo al hacer algún arreglo con el Frente Sandinista pudieran manejarlo todo...".

De este modo, el Pacto de 2000 incrementaría los miembros de la Corte del 12 a 16 y aunque inicialmente estos estaban alineados en favor del PLC, con 3 independientes, a lo largo del tiempo las sucesivas elecciones de los magistrados para reemplazar aquellos cuyos mandatos expiraban ha hecho que el PLC y el FSLN se repartan dichos puestos hasta alcanzar un empate de miembros 8-8 en 2007 (Cuadro 7).

Cuadro 7: Fuerzas políticas representadas en la Corte Suprema de Nicaragua (2009)

\begin{tabular}{ll}
\hline \multicolumn{1}{c}{ FSLN (8) } & \multicolumn{1}{c}{ PLC (8) } \\
\hline Alba Luz Ramos & Iván Escobar Fornos \\
Rafael Solís & Guillermo Selva \\
Armengol Cuadra & Damisis Sirias \\
Yadira Centeno & Manuel Martínez \\
Marvin Aguilar & Edgar Navas Navas \\
Francisco Rosales & Sergio Cuarezma Terán \\
Ligia Molina & José Antonio Alemán Lacayo \\
Juana Méndez Pérez & Gabriel Rivera \\
\hline
\end{tabular}

Fuente: Elaboración propia basada en Lourdes Arróliga: "Bancada en la Corte". Confidencial. 15-21 junio del 2003 y colaboraciones anónimas.

43 Los magistrados de la Corte Suprema ahora son propuestos por el Ejecutivo y la Asamblea Nacional a través de una lista en consulta con asociaciones civiles. Sin embargo, en realidad es la Asamblea Nacional quien elige a los magistrados a través de un $60 \%$ de sus votos, lo que implica que se necesita un gran consenso en su nombramiento que ha generado en realidad el reparto de cargos.

44 Entrevista realizada al ex magistrado de la Sala Constitucional de la Corte Suprema, Vargas Sandino (Managua, 7 de septiembre de 2005). 
Pero la alta "disciplina" de los magistrados se debe principalmente a la reducción de su mandato de 7 a 5 años con la posiblidad de reelección (art. 161) y posibilitando su pérdida de inmunidad con tan solo el voto de mayoría simple en la Asamblea Nacional (arts. 130.3 y 162). Esta reducción del período en el cargo junto con las bajas garantías en el cargo significan que, en términos generales, los jueces están más expuestos a presiones políticas. Cuando se les preguntó por la duración de su mandato, todos los magistrados de la Corte Suprema entrevistados propusieron aumentar el período en el cargo para evitar la "politización" de sus cargos y no depender de los deseos de los legisladores. Así el magistrado Solís indicaba: ${ }^{45}$

"...ahorita el período es muy corto y eso a veces se presta a presiones políticas o a malos entendidos de que cuando ya te falta un año obviamente para salir, tenés más presión de los diputados en casos tal vez políticos porque sabés que si no, no te pueden reelegir y a lo mejor querés ser reelecto y terminar en la Corte tu carrera".

Esto pone de manifiesto que dado el rol primordial que tienen los partidos en la selección y reelección de los magistrados, no puede sorprender a nadie que los magistrados no "militen" a favor del partido de quien depende su nombramiento y permanencia en el cargo. Este patronazgo político es algo que reconocen desde los diputados ${ }^{46}$ hasta los mismos magistrados que consideran que la relación con el gobierno $(63,6 \%)$ o haber pertenecido a un partido $(61,8 \%)$ son factores determinantes para ser nombrado para el alto órgano judicial. ${ }^{47}$

El magistrado Rafael Solís hace referencia a la histórica cooptación política de la Corte Suprema sin entender las actuales críticas a la misma:

"[... ] antes, cuando eran los abogados de las grandes empresas los que venían aquí a la CSJ... no se decía que la Corte estaba cooptada por el sector empresarial de Nicaragua...cuando así era...en la época de la Sra. Chamorro...y todavía en los primeros años del Dr. Alemán... todo fue que el FSLN lograra pasar de dos magistrados que originariamente habian sido sandinistas y que estaban en la Corte, Alba Luz Ramos y otro más, a tener ahora mayor número de lo que fue...que vinieron propuestos por la bancada de diputados sandinistas para que se diga que aquí la Corte la cooptan los partidos".

Pero lo que el magistrado Solís pone también de manifiesto es que esta "cooptación" política de la Corte Suprema se ha venido fraguando desde hace tiempo. Así, Dye (2004: 48) indica que todos los magistrados tienen lealtades políticas claras y que la imposición de órdenes partidistas sobre las decisiones judiciales se organiza de un modo sutil, aparecen como esporádicas y descentralizadas y envuelven a múltiples

45 Entrevista realizada al magistrado de la Sala Constitucional de la Corte Suprema Rafael Solís (Managua, 6 de septiembre de 2005).

46 Los diputados nicaragüenses mencionan principalmente el sistema de elección (42,2\%) como principal obstáculo para la independencia judicial. Respuestas a la pregunta(n.25a): “Cuál es en su país el principal obstáculo para que el Poder Judicial actúe de forma independiente?" (PELA 2002).

47 Respuestas a la pregunta (n. 16): “¿Podría decirme qué grado de importancia estima que tienen los siguientes factores que le menciono para el nombramiento de los jueces?". Sólo se incluyen las respuestas "muy importante" e "importante" (JDCA 2004). 
redes de fidelidad de tal modo que todos los hilos conductores llevan tanto a Arnoldo Alemán como a Daniel Ortega. En la realidad, esto implica que las decisiones judiciales arbitrarias aparecen más como consecuencia de negociaciones entre los magistrados que como instrucciones directas por parte de los líderes políticos dominantes. En este mismo sentido el periodista Carlos Chamorro indica como:

"Ortega descubrió en la oposición que el poder de los jueces puede ser más destructivo que un AK47. Un verdadero ejército de operadores políticos judiciales se construyó de forma paciente, durante dieciséis años, hasta cooptar el Poder Judicial. Conspiradores que ayer se jugaron la vida por un ideal, ahora transfigurados en abogados de cursos sabatinos, pasaron a ocupar cargos como jueces, fiscales o magistrados de la Corte Suprema de Justicia, al servicio exlusivo de Ortega y de sus intereses políticos y económicos" (Declaraciones en La Jornada México y en Confidencial, 27 diciembre-10 enero: "El poder de la demagogia revolucionaria de Daniel Ortega").

Esta circunstancia ya ha sido señalada años atrás por algunos magistrados. En este sentido, el ex magistrado Guillermo Vargas Sandino, confesaba abiertamente:

"[... ...no se elige a la persona porque sea una persona seria, honesta y preparada, sino quien tiene un mayor peso político o quien pueda servirles más políticamente...eso ha sido en las últimas elecciones".

Incluso iba más allá al indicar la existencia de bancadas en la Corte a semejanza de la Asamblea Nacional:

“...prácticamente la Asamblea Nacional está dividida en bancadas... una bancada liberal y una bancada sandinista... pues también aquí en la Corte hay una bancada liberal y una bancada sandinista... es una segunda Cámara Legislativa... y eso no puede ser... de ninguna manera...eso no es posible...no se ha visto en ninguna parte ninguna situación como ésta... Esto debería ser una cuestión pluralista, una cuestión de ideas jurídicas para resolver los asuntos y no a efectos meramente políticos".

Esto se refuerza cuando se les pregunta a los magistrados por su autoubicación. Así, en una escala de 10 puntos donde 1 representa el extremo de izquierda y 10 el de derecha, ellos se sitúan como media en un 4,20, con una desviación estándar de 2,34, lo que manifiesta las grandes diferencias ideológicas que existen entre los magistrados reforzando así la teoría de las bancadas en la Corte. ${ }^{48}$

Así las cosas, no es de extrañar que la Corte admitiera el recurso de dudosa legalidad y en tiempo récord sentenciara a favor de Daniel Ortega. Así, observando el Cuadro 8 podemos ver cómo los únicos magistrados que integraron ese día la Sala Constitucional fueron los sandinistas (Francisco Rosales, Rafael Solís, Ligia Molina, Yadira Centeno, Armengol Cuadra y Juana Méndez), tanto los titulares como los suplentes (que sustituían

48 Respuestas a la pregunta: “Cuando se habla de política se utilizan normalmente las expresiones izquierda y derecha. En una escala donde el 1 es la izquierda y el 10 la derecha, ¿en qué casilla se colocaría Ud. teniendo en cuenta sus ideas políticas?" (Fuente: JDCA). 
en este caso a los magistrados "ausentes", justamente todos ellos liberales). Guardando las distancias, es posible encontrar similitudes con la estrategia seguida por Óscar Arias, sólo que en el caso de Ortega, éste no esperó a tener una mayoría complaciente, sino que la fabricó incorporando por una tarde a tres magistrados leales al FSLN, para que le dieran en unas horas esta posibilidad. No tenía ninguna duda de su control en la más alta instancia judicial, lo que la convertía en el foro perfecto para dirimir la cuestión de la constitucionalidad de la prohibición de reelección presidencial.

Cuadro 8: Composición de la Sala Constitucional de la Corte Suprema de Justicia en la sentencia de 2009

\begin{tabular}{llllc}
\hline \multicolumn{1}{c}{ Nombre } & \multicolumn{1}{c}{ Período } & $\begin{array}{c}\text { Principal } \\
\text { apoyo } \\
\text { partidista }\end{array}$ & $\begin{array}{l}\text { Cargo } \\
\text { en la } \\
\text { Sala }\end{array}$ & $\begin{array}{c}\text { Decisión } \\
\text { reelección } \\
\text { Ortega }\end{array}$ \\
\hline Rafael Solís Cerda & $($ 1997-actualidad) & FSLN & Titular & Sí \\
Armengol Cuadra López & $($ 1997-actualidad) & FSLN & Suplente & Sí \\
Francisco Rosales Arguello & $($ 1997-actualidad) & FSLN & Titular & Sí \\
Yadira Centeno González & $($ 1997-actualidad) & FSLN & Suplente & Sí \\
Guillermo Selva Arguello & $($ 1997-actualidad) & PLC & Suplente & \\
Iván Escobar Fornos & $($ 1997-actualidad) & PLC & Titular & \\
Ligia Molina Arguello & $($ 2003-actualidad) & FSLN & Titular & Sí \\
José Damisis Sirias & $($ 2003-actualidad) & PLC & Titular & \\
Juana Méndez Pérez & $($ 2007-actualidad) & FSLN & Suplente & Sí \\
Sergio Cuarezma Terán & $($ 2007-actualidad) & PLC & Titular & \\
José Antonio Alemán Lacayo & $($ 2008-actualidad) & PLC & Suplente & \\
Gabriel Rivera & $($ 2008-actualidad) & PLC & Suplente & \\
\hline
\end{tabular}

Fuente: Elaboración propia.

Pero en ningún momento los magistrados de la Corte Suprema cuestionan su rol proactivo dentro del sistema. ${ }^{49}$ En este sentido son conscientes de la importancia política de sus decisiones, pero a diferencia de los magistrados costarricenses, en Nicaragua muchos magistrados de la Corte Suprema van más lejos confesando pública y abiertamente sus inclinaciones partidistas. En este sentido el magistrado Solís reconoce sin tapujos que ha sido sandinista y que esto influye necesariamente en sus decisiones: "he sido sandinista, una vez que venimos aquí... nos apartamos de la vida política partidaria... pero sí mantenemos obviamente nuestras simpatías con esa fuerza...". Incluso va más lejos: “...en algunos casos estrictamente politicos donde sí podés decir'el Dr. Rafael Solís no fue contra el sandinismo, porque obviamente es sandinista, ipues!'). Reconoce también seguir su ideología política a la hora de decidir los casos siempre que las circunstancias políticas le permitan hacerlo: 
"[...] yo no soy de los magistrados que van a venir aquí a decir...'bueno ahora soy magistrado, pero reniego del sandinismo o de ser lo que he sido'...pues no y lo he dicho públicamente $y$ me ha costado mucho eso... pero es mi forma de ver la vida y de ver el mundo, pues...antes que magistrado, he sido una persona comprometida con un cargo de Nicaragua, todavía creo que se puede volver a ser más adelante...pero eso aquí se malinterpreta y te encajonan en determinado sentido como que el magistrado tuviera que borrar totalmente cualquier tipo de compromiso político pues...y no es así pues... porque tampoco los otros lo hacen...los que han venido representando a los banqueros, a los empresarios de Nicaragua, y a determinados periódicos de Nicaragua lo han seguido haciendo cuando han sido magistrados, pues...no hay que ser hipócrita en ese sentido".

Así, no es de extrañar que el magistrado Solís, vicepresidente de la Corte Suprema de Justicia, indique a la hora del fallo de la sentencia "reeleccionista": "desde el punto de vista político se solucionó el problema de la reelección que es importante para que el comandante (Daniel Ortega) vuelva a correr como candidato" (Declaraciones a Confidencial, 20 de diciembre-10 enero de 2010). Ni tampoco que el magistrado Francisco Rosales, presidente de Sala Constitucional, peregrine por distintos canales de televisión, exponiendo como argumento fundamental el artículo 48 constitucional que establece la igualdad de condiciones de todos los nicaragüenses en el goce de sus derechos políticos (Confidencial, 25 al 31 de octubre de 2009).

Teniendo en cuenta todas estas variables, los resultados del análisis del caso nicaragüense no sorprenden: las fuertes diferencias ideológicas y las orientaciones políticas influyen en el comportamiento de los magistrados conviriéndose así el foro jurisdiccional en otro foro político más.

\section{A MODO DE REFLEXIÓN: ABRIENDO LAS PUERTAS A LA JUDICIALIZACIÓN DE LA REELECCIÓN PRESIDENCIAL}

A lo largo de este estudio se ha tratado de explicar la judicialización de las disputas sobre la reelección presidencial. Podemos concluir que, en general, el análisis de los casos se muestra consistente con el modelo propuesto y la evidencia empírica confirma las hipótesis teóricas propuestas inicialmente. En este sentido, en ambos países el juego "reeleccionista" se ha trasladado al ámbito judicial cuando los pretendientes a la reelección han sido conscientes de que no disponían de mayorías legislativas para llevar a cabo una reforma constitucional, pero sabían que su propuesta sería apoyada tanto por las Cortes como por la sociedad. En este sentido, para elegir el foro judicial como dirimidor de la decisión sobre la reelección presidencial es necesario que el pretendiente a la misma crea que tiene el apoyo necesario para ganarla y crea controlar la Corte sin disponer de apoyo suficiente en el Legislativo para efectuar el cambio constitucional. Todo esto es más probable en el caso de una coalición dominante o ascendente.

Esta inclusión de los actores judiciales en el juego político que puede conllevar efectos positivos para el sistema dada su capacidad para garantizar la protección de minorías y la protección constitucional, también puede tener efectos perniciosos. Esto se debe a que 
el emponderamiento de las Cortes Supremas puede provocar una cierta fragmentación del poder que paralice los procesos de decisión, favoreciendo con frecuencia una menor transparencia. Esto podría erosionar radicalmente la responsabilidad política, es decir, el principio democrático fundamental de que siempre hay un responsable de las decisiones que afectan a la comunidad. Así, el sistema se ve claramente dañado cuando los actores políticos no asumen su función "despolitizando" temas sensibles aceptando e incluso promoviendo su transferencia a la esfera judicial para no asumir los costos políticos. Esto sucede cuando se ha suprimido la decisión política, aparentemente a favor del derecho, otorgando así mayor éxito a los grupos o actores políticos que disponen de recursos para emplearlos eficazmente en el circuito judicial.

Esto es lo que ha sucedido en los casos estudiados en el que dos actores políticos-Óscar Arias y Daniel Ortega, con recursos suficientes para emplearlos en el foro judicial y conscientes de su apoyo político y social, han preferido entonces "judicializar" el tema interponiendo sendos recursos ante la Corte Suprema de sus países. La comparación de dos casos "positivos" nos ha permitido identificar potenciales condiciones necesarias para el resultado, aunque no nos ha facultado a saber si estas condiciones son suficientes para el mismo. Será necesario en el futuro incluir más casos (muchos de ellos negativos) para poderla testar mejor. Del mismo modo es interesante en futuras investigaciones estudiar la importancia que tienen en el sistema los diferentes actores políticos que presentan este tipo de recursos y cómo estos influyen no sólo en el traslado de la cuestión del foro político al judicial sino su éxito en la alta instancia judicial.

Podríamos indicar entonces que cuando judicializar la política implique dar cada vez más y más poder a quien no puede ser sustituido reduciendo el espacio de toma de decisiones del Legislativo o Ejecutivo por temor a ser sujetos de responsabilidad, nos encontraremos ante una perversión de la "judicialización de la política" o, en palabras de Uprimny, ante una "judicialización democráticamente riesgosa" (2007: 67). Pero no sólo podemos culpabilizar a actores externos de este tipo de judicializaciones "no democratizantes"; los jueces deben autolimitarse para proteger su "imparcialidad" en el sistema y poder seguir operando de un modo políticamente significativo, ya que en cualquier caso una magistratura difícilmente podrá obrar con eficacia si no dispone de algún sustento en la sociedad o en el sistema político.

Para concluir, podríamos indicar que si bien es cierto que las Cortes Supremas están jugando un papel fundamental en las actuales democracias de América Latina, las batallas para la renovación y los cambios politicos -siguiendo a Koopmans (2003)- se deben llevar a cabo en las urnas y no en las Cortes.

\section{BASES DE DATOS UTILIZADAS}

JDCA. 2004. Proyecto Política de Justicia y Calidad de la Democracia en Centroamérica. Universidad de Salamanca, Comisión Interuniversitaria de Ciencia y Tecnología. CICYT (SEC 20001-1779).

PELA. 2002. Proyecto de Investigación Elites Parlamentarias Iberoamericanas. Instituto de Estudios de Iberoamérica y Portugal, Universidad de Salamanca. 


\section{REFERENCIAS}

Ansolabehere, Karina y Martínez-Barahona, Elena. 2009. “Judicial Politics in Latin America. Twenty years of political analysis about the judiciary". Presentado en XXVIII Meeting of the Latin American Studies Association (LASA) (11-14 Junio). Rio de Janeiro (Brasil).

Barak, Aharon. 1989. Judicial Discretion. New Haven: Yale University Press.

Bybee, Keith. 2000. "The Political Significance of Legal Ambiguity: The Case of Affirmative Action". Law and Society Review 34 (2): 263-290.

Buquet, Daniel. 2007. “Entre la legitimidad y la eficacia: reformas en los sistemas de elección presidencial en América Latina". Revista Uruguaya de Ciencia Política 16 (1): 35-49.

Close, David. 2003. "Political Parties and Democracy in Nicaragua: Not Yet, Maybe Someday". Presentado en Joint Sessions of Workshops of the European Consortium for Political Research (28 de marzo-2 de abril). Edinburgh.

Close, David y Marti, Salvador (eds.) 2009. Nicaragua y el FSLN (1979-2009) ¿Qué queda de la revolución? Barcelona: Editorial Bellaterra.

Collier, David, James Mahoney y Jason Seawright. 2004. "Claiming Too Much: Warnings about Selection Bias". En Rethinking Social Inquiry. Diverse Tools, Shared Standards, editado por H. E. Brady y D. Collier. Lanham: Rowman \& Littlefield, 85-102.

Dion, Douglas. 1998. "Evidence and Inference in the Comparative Case Study". Comparative Politics 30 (2): $127-146$.

Domingo, Pilar. 2004. "Judicialization of Politics or Politicization of the Judiciary? Recent Trends in Latin America" Democratization 11 (1): 104-126.

Dye, David. 2004. Democracy Adrift: Caudillo Politics in Nicaragua. Managua: PRODENI.

Fernández Sáenz, Guido. 2003. Piedra Azul: Atisbos en mi vida. San José: Editorial Costa Rica.

Gauri, V. and Brinks, D. 2008. Courting Social Justice. Judicial Enforcement of Social and Economic Rights in the Developing World. Cambridge: Cambridge University Press.

Geddes, Barbara. 2003. Paradigms and Sand Castles: Theory Building and Research Design in Comparative Politics. Ann Arbor: University of Michigan Press.

Gibson, James. 1983. "From Simplicity to Complexity: The Development of Theory in the Study of Judicial Behavior". Political Behavior 5 (1): 7-49.

Ginsburg, Tom. 2003. Judicial Review in New Democracies. Constitucional Courts in Asian Cases. Cambridge: Cambridge University Press.

Guarnieri, Carlo 2005. "El gobierno de los jueces en Europa". Revista puente@Europa. El Gobierno de los Jueces 3 (1): 28-33.

Handberg, Roger, Wilson, Bruce and Gaal, Michael. 2001. "Comparing Activist National Courts: Hungary and Costa Rica". Presentado en Annual Meeting of the American Political Science Association (30 agosto-2 septiembre). San Francisco.

Iaryczower, Pablo Spiller and Mariano Tommasi. 2002. "Judicial Decision Making in Unstable Environments: Argentina 1938-1998". American Journal of Political Science 46 (4): 699-716.

Kapiszewski, Diana. 2009. “Tactical Balancing and Prioritizing Pragmatism: High Court Decision-Making on Economic Policy Cases in Brazil". Presentado en Conference Judicial Politics in Latin America (4-8 marzo 2009). CIDE, Mexico, D.F.

Kapiszewski, Diana and Taylor, Matthew M. 2008. "Doing Courts Justice? Studying Judicial Politics in Latin America". Perspectives on Politics 6 (4): 741-767.

King, G., Keohane, R. and Verba, S. 1994. Designing Social Inquiry. Princeton, N.J: Princeton University Press.

Koopmans, Tim. 2003. Courts and Political Institutions. A Comparative View. Cambridge: Cambridge University Press.

López-Ayllón, Sergio and Hector F. Fix-Fierro. 2003. "Faraway, So Close!". The Rule of Law and Legal Change in Mexico 1970-2000" en Legal Culture in the Age of Globalization: Latin America and Latin 
Europe, editado por Lawrence Friedman y Rogelio Pérez-Perdomo. Stanford, CA: Stanford University Press, 285-351.

Magalhães, Pedro. 2003. The Limits to Judicialization: Legislative Politics and Constitutional Review in the Iberian Democracies. Unpublished Dissertation. Political Science Graduate School. Ohio State University.

Martínez-Barahona, Elena 2009. Seeking the Political role of the Third Government Branch: A Comparative Approach to High Courts in Central America. Saarbrücken (Alemania): VDM Verlag Dr. Müller.

Martínez-Barahona, Elena 2009b. "El sistema judicial: ¿el 'secuestro' politico de una Corte Suprema?", en ¿Qué queda de la revolución? Nicaragua y el FSLN (1979-2009), editado por David Close y Salvador Marti. S. Barcelona: editorial Bellaterra, 221-264.

Moustafa, Tamir. 2003. "Law versus the State: The Judicialization of Politics in Egypt", Law and Social Inquiry 28 (4): 883-930.

Pérez Liñán, Aníbal. 2007. "El Método Comparativo: Fundamentos y Desarrollos Recientes", Documento de Trabajo, Universidad de Pittsburgh.

Przeworski, Adam and Henry Teune. 1970. The Logic of Comparative Social Inquiry. New York: WileyInterscience.

Ragin, Charles C. 2000. Fuzzy-Set Social Science. Chicago: The University of Chicago Press.

Rodríguez Iglesias, Gil Carlos. 2004. "The Judges Confronts Himself as Judge”, en Judges in Contemporary Democracy. An International Conversation, editado por R. Badinter y S. Breyer. New York and London: New York University Press, 275-316.

Segal, Jeffrey A. and Spaeth, Harold J. 2002. The Supreme Court and the Actitudinal Model Revisited. Cambridge: Cambridge University Press.

Shapiro, Martin and Stone Sweet, Alec. 2002. On Law, Politics, and Judicialization. Oxford: Oxford University Press.

Smulovitz, Catalina and Enrique Peruzzotti. 2003. "Societal and Horizontal Controls: Two Cases of a Fruitful Relationship", en Democratic Accountability in Latin America, editado por Scott Mainwaring and Christopher Welna. Oxford: Oxford University Press, 309-343.

Staton, Jeffrey. 2002. "Judicial Activism and Public Authority Compliance: The Role of Public Support in the Mexican Separation-of-Powers System". Tesis Doctoral. Department of Political Science. Washington University.

Solís Fallas, Alex. 2000. La Dimensión Política de la Justicia Constitucional. San José de Costa Rica: Impresión Gráficas del Este.

Sousa Santos, Boaventura. 1996. Os tribunais nas sociedades contemporaneas: o caso portugues. Lisbon: Afrontamento.

Scheb, John, Ungs, Thomas and Hayes, Allison. 1989. "Judicial Role Orientations, Attitudes and Decision Making: A Research Note". Western Political Quarterly 42 (4): 427-435.

Staats, Joseph. 2006. "Role Orientation, Policy Preferences, and Attitudes Towards Democracy of Judges in Honduras and Uruguay". Presentado en XXVI Meeting of the Latin American Studies Association (LASA) (15-18 marzo). Puerto Rico.

Tate, Neal. 2007. "Comparative Judicial Politics". Committee on Concepts and Methods. Working Paper Series. C\&M, IPSA y CIDE.

Tsebelis, George. 2002. Veto Players. How Political Institutions Work. New York and Priceton, New Jersey: Russell Sage Foundation and Priceton University Press.

Uprimny, Rodrigo. 2007. “La judicialización de la política en Colombia: casos, potencialidades y riesgos". Sur. Revista Internacional de Derechos Humanos 4 (6): 52-69.

Volcansek, Mary. 2001. "Constitutional Courts as veto players: divorce and decrees in Italy". European Journal of Political Research 39 (3): 347-372.

Wilson, Bruce. 1998. Costa Rica: Politics, Economics, and Democracy. Boulder: Lynne Rienner.

Wilson, Bruce. 2004. "Changing Dynamics: The Political Impact of Costa Rica's Constitutional Court". Presentado en Conference of Judicialization of Politics in Latin America (11 de marzo). ILAS, Londres. 
Wilson, Bruce and Handberg, Roger. 1998. “Opening Pandora's Box: The Unanticipated Political Consequences of Costa Rican Legal Reform". Presentado en Midwest Political Science Association (12-15 Abril). Palmer House Hilton, Chicago.

Elena Martínez-Barahona es Licenciada en Derecho y en Ciencia Política por la Universidad de Salamanca y Doctora en Ciencia Política por el European University Institute (Florencia). Actualmente es Profesora en el Área de Ciencia Política e Investigadora del Instituto de Iberoamérica de la Universidad de Salamanca. Es autora de artículos sobre política latinoamericana en revistas especializadas y coeditora de La Justicia vista por los jueces (2004), y Política, dinero e institucionalización en los partidos de América Latina (2003). Su último libro es Seeking the political role of the third government branch. A comparative approach to High Courts in Central America (2009). Es la investigadora principal del proyecto "Seguridad Ciudadana y Democracia en América Latina" financiado por la CICYT-España (2009-2011). Sus intereses de investigación se centran en política comparada y latinoamericana, especialmente en instituciones y políticas judiciales, justicia transicional, derechos humanos y temas de seguridad ciudadana y violencia. 